\title{
CORRESPONDENCE
}

\section{Smoking and COPD: what really are the risks?}

\section{To the Editors:}

Chronic obstructive pulmonary disease (COPD) is rapidly becoming a global public health crisis, with around three million people predicted to die from the disease in 2006 [1, 2]. There is growing awareness of the increasing global burden of COPD not only in terms of mortality, but also its prevalence, morbidity and economic costs [2]. In response to these concerns, there has been a renewed research effort to understand the causes of COPD and to develop public health and pharmacological interventions that may reduce the burden.

Smoking is recognised as the most important causative factor for COPD, with an individual's susceptibility being a continuous, rather than a categorical characteristic that can interact synergistically with other risk factors. There is now evidence that most smokers develop some respiratory impairment due to COPD [3]. One of the most informative recent studies addressing this issue is the Obstructive Lung Disease in North Sweden (OLIN) study [4]. From this cohort study, it was reported that $\sim 50 \%$ of smokers eventually develop COPD, as defined according to the Global Initiative for Chronic Obstructive Lung Disease (GOLD) guidelines [2]. This finding is of major clinical significance, in that it provides a scientific basis for the advice that can now be given to smokers that if they continue smoking lifelong, they have at least a one in two chance of developing COPD. Importantly, the study also provides evidence that the risk of developing COPD falls by about half with smoking cessation.

The OLIN study also allowed determination of the proportion of COPD cases that is due to smoking [4]. Utilising the GOLD criteria for the diagnosis of COPD, the population attributable risk of COPD for smoking was $45 \%$ (95\% confidence interval (CI) $29-58 \%$ ) in the 46-77-yr age group. Utilising the British Thoracic Society criteria [5], which are considerably more stringent than the GOLD criteria for the diagnosis of COPD, the population attributable risk was 50\% (95\% CI 28-67\%). This population attributable risk is considerably less than current dogma suggests, with a figure of $80-90 \%$ commonly quoted [68]. A comparable population attributable risk of $44 \%$ (95\% CI $38-50 \%$ ) can be calculated from the third National Health and Nutrition Examination Survey (NHANES III) [9]. However, this figure is qualified by the lack of post-bronchodilator lung function measurements in the NHANES III, which means that the COPD criteria employed were more inclusive of cases with asthma.

If only about half of all cases of COPD are due to smoking, what factors are responsible for the other half and what can be done to reduce their impact? It is not widely recognised that up to $20 \%$ of cases of COPD worldwide can be attributed to indoor air pollution from exposure to smoke from cooking and heating with biomass fuels in poorly ventilated dwellings
$[10,11]$. This is likely to explain the similar prevalence of COPD in females and males in developing countries, despite markedly lower rates of smoking in females [2]. Greater recognition of the role of indoor air pollution is a necessary prerequisite for the development of strategies to lessen its impact, and to reduce the occurrence of COPD.

A comparable example, which is amenable to public health and government interventions, is workplace exposure to a wide variety of dusts, chemicals and fumes. Given that up to $20 \%$ of cases of COPD may be attributed to occupational exposures [12], the potential benefit of preventive measures are apparent. As with indoor air pollution, the greatest burden of COPD due to occupational exposures is in the developing world. Other risk factors that could potentially be modified at an individual or population level are outdoor air pollution, marijuana smoking, chronic respiratory infection, diet, childhood asthma and factors associated with lung growth in utero and infancy.

We suggest that a greater understanding of the causation of chronic obstructive pulmonary disease is a research priority to provide the basis for the development of primary and secondary intervention programmes. This recommendation does not lessen the significance of tobacco smoking as the most important cause of chronic obstructive pulmonary disease, or the public health importance of measures to reduce tobacco consumption internationally. Smoking remains an important cause of global mortality, being accountable for around five million premature deaths in the world every year, including about one million due to chronic obstructive pulmonary disease [13].

\section{S. Marsh*, S. Aldington*, P. Shirtcliffe*, M. Weatherall ${ }^{*}$ and R. Beasley*,}

*Medical Research Institute of New Zealand, and "Wellington School of Medicine \& Health Sciences, Wellington, New Zealand. "University of Southampton, Southampton, UK.

\section{REFERENCES}

1 Pauwels RA, Rabe KF. Burden and clinical features of chronic obstructive pulmonary disease (COPD). Lancet 2004; 365: 613-620.

2 Global Initiative for Chronic Obstructive Lung Disease. Global Strategy for the Diagnosis, Management and Prevention of COPD. www.goldcopd.com. Date last accessed: July 13 2006. Date last updated: 2005.

3 Rennard SI, Vestbo J. COPD: the dangerous underestimate of $15 \%$. Lancet 2006 ; 367: 1216-1219.

4 Lundback B, Lindberg A, Lindstrom M, et al. Not 15 but $50 \%$ of smokers develop COPD? Report from the 
Obstructive Lung Disease in Northern Sweden Studies. Respir Med 2003; 97: 115-122.

5 British Thoracic Society. Guidelines for the management of chronic obstructive pulmonary disease. Thorax 1997; 52: Suppl. 5, S1-S28.

6 Calverley PMA, MacNee W, Pride NB, Rennard SI, eds. Chronic Obstructive Pulmonary Disease. 2nd Edn. London, Arnold, 2003.

7 Mannino DM. COPD: epidemiology, prevalence, morbidity and mortality, and disease heterogeneity. Chest 2002; 121: Suppl. 5, 121S-126S.

8 US Surgeon General, ed. The Health Consequences of Smoking: Chronic Obstructive Lung Disease. Publ No. 8450205. Washington DC, USDHHS, 1984.

9 Mannino DM, Buist AS, Petty TL, Enright PL, Redd SC. Lung function mortality in the United States: data from the first National Health and Nutrition Examination Survey follow up study. Thorax 2003; 58: 388-393.

10 World Health Report 2002. Message from the DirectorGeneral, Dr GH Brundtland. Overview. Geneva, World Health Organization, 2002; pp. ix-xx.

11 World Health Report 2002. Message from the DirectorGeneral, Dr GH Brundtland. Quantifying selected major risks to health. Geneva, World Health Organization, 2002; pp. 68-76.

12 Trupin L, Earnest G, San Pedro M, et al. The occupational burden of chronic obstructive pulmonary disease. Eur Respir J 2003; 22: 462-469.

13 Ezzati M, Lopez AD. Estimates of global mortality attributable to smoking in 2000. Lancet 2003; 362: 847-852.

\section{High prevalence of abnormal acid gastro-oesophageal reflux in idiopathic pulmonary fibrosis}

\section{To the Editors:}

The role of gastro-oesophageal reflux in idiopathic pulmonary fibrosis (IPF) has been given little consideration in the literature, and RAGHU et al. [1] have made a significant contribution in this regard. However, if we examine their data in terms of attributable risk, the potential clinical impact of these findings becomes even clearer.

Several other reports have suggested a possible link between gastro-oesophageal reflux and IPF. A case-control study from 1976 determined the prevalence of reflux to be higher in 48 patients with IPF than in 270 age-matched controls with fibrosis of other aetiologies [2]. TOBIN et al. [3] previously published a smaller case-control study which identified that 16 out of $17(94 \%)$ patients with IPF compared with four out of eight $(50 \%)$ patients with interstitial lung disease due to other causes had abnormal acid exposure in the oesophagus. In 2005, PATTI et al. [4] determined the prevalence of gastrooesophageal reflux in IPF patients to be $66 \%$, with a third of those patients having no reflux symptoms.

In the current study, 46 patients with IPF not currently receiving proton pump inhibitor (PPI) therapy were compared with 133 asthmatics also not receiving PPI therapy. All patients were subjected to 24-h $\mathrm{pH}$-probe testing. The prevalence of abnormal acid exposure was 87 and $68 \%$ in IPF patients and asthmatics, respectively (statistically significant, $\mathrm{p}=0.014$ ). Thus, the odds of having IPF in those with abnormal acid exposure as compared to those without (odds ratio) is 3.19. The attributable risk percentage (ARP) calculated based on table 1, which was constructed using data from the study by RAGHU et al. [1], is $68.6 \%$. If we assume a causal relationship between reflux and IPF, then simply stated the ARP means that $68.6 \%$ of the cases of IPF in patients with abnormal acid exposure would not have occurred in the absence of exposure. The population
ARP is $49.8 \%$, which means that in the population of patients studied, almost half of IPF cases identified would not have occurred in the absence of abnormal acid exposure.

Unfortunately, the data presented by RAGHU et al. [1] also suggest that only $47 \%$ of patients with abnormal acid exposure experienced gastrointestinal symptoms, meaning that symptom-targeted therapy may not be effective. Given the relatively low cost of proton pump inhibitor therapy and low side-effect profile compared with other available therapies for idiopathic pulmonary fibrosis, these data suggest that at the very least treatment with a proton pump inhibitor should be strongly considered in patients with idiopathic pulmonary fibrosis until better data are available. The data presented by RAGHU et al. [1] also showed that 12 out of 19 patients on proton pump inhibitors still had abnormal results from $\mathrm{pH}$ probe studies. More research needs to be carried out regarding the association between reflux and idiopathic pulmonary fibrosis to determine whether even more aggressive therapies should be considered, should treatment with proton pump inhibitors fail to adequately treat reflux.

\begin{tabular}{lccc} 
TABLE 1 & $\begin{array}{l}\text { Frequency of gastro-oesophageal reflux in } \\
\text { patients with IPF and asthma }\end{array}$ \\
& IPF cases & Asthma controls & Totals \\
\hline GERD+ & 40 & 90 & 130 \\
GERD- & 6 & 43 & 49 \\
Totals & 46 & 133 & 179 \\
\hline & & \\
Data are presented as n. IPF: idiopathic pulmonary fibrosis; GERD: gastro- \\
oesophageal reflux disease; +: positive; -: negative.
\end{tabular}

